\title{
HER2/Neu Negative by Immunohistochemistry
}

National Cancer Institute

\section{Source}

National Cancer Institute. HER2/Neu Negative by Immunohistochemistry. NCI

Thesaurus. Code C141480.

A laboratory test result indicating the absence of HER2/Neu in a tissue sample using immunohistochemical staining. 